\title{
A rare clinical case of synchronous colorectal cancer, affecting the transverse
}

\section{colon}

\author{
Strahil Strashilov ${ }^{1}$ Angel Yordanov²
}

1. Department of Plastic Restorative, Reconstructive and Aesthetic Surgery, Medical University Pleven, Bulgaria

2. Clinic of Gynecologic Oncology, Medical University Pleven, Bulgaria

\section{Corresponding Author:}

Angel Danchev Yordanov

Clinic of Gynecologic Oncology, University Hospital "Dr.

Georgi Stranski", Medical University Pleven, Georgi Kochev 8A, Bulgaria

Email: angel.jordanov@gmail.com

\section{ABSTRACT}

Synchronous colorectal cancer is a rare condition, which presents with the simultaneous development of more than one primary carcinoma and affects different segments of the colon and rectum. The incidence of this disease is about 3.5 per cent of all carcinomas of the colon and rectum and more often affected men. Adenocarcinoma is the most common histological type for synchronous colorectal cancer.

We present a rare clinical case of a 62-year-old woman with synchronous colorectal carcinoma, located in the transverse and sigmoid colon and verified histologically by colonoscopy.

\section{Key Words}

Colorectal cancer, synchronous colorectal cancer, colorectal adenocarcinoma

\section{Implications for Practice:}

\section{What is known about this subject?}

Synchronous colorectal cancer is a rare condition. Its incidence is about 3.5 per cent of all carcinomas that involve the colon and rectum.

\section{What new information is offered in this case study?}

The two synchronous colon carcinomas are of the same histology but with different malignant potential.

3. What are the implications for research, policy, or practice?

It complements the knowledge about synchronous colorectal carcinoma.

\section{Background}

Synchronous colorectal cancer is a relatively rare condition, which presents with the simultaneous development of more than one primary carcinoma and affects different segments of the colon and rectum. Its incidence is about 3.5 per cent of all carcinomas that involve the colon and rectum. ${ }^{1}$ The gender distribution of this disease in females and males is respectively $1: 1.8,{ }^{2-6}$ mean age $63 .^{7-11}$ Adenocarcinoma is the most common histological type for synchronous colorectal cancer. $^{12}$

We present a rare clinical case of a 62-year-old woman with synchronous colorectal carcinoma, located in the transverse and sigmoid colon and verified histologically by colonoscopy.

\section{Case details}

We present a 62-year-old woman with comorbidities of arterial hypertension, chronic bronchitis and pulmonary emphysema. She was initially admitted to the Clinic of Gastroenterology and Hepatology in Dr. Georgi Stranski University Hospital in Pleven, Bulgaria. The patient presented with persistent constipation, continuing for years 
and hardly affected by laxatives, and clinical and laboratory signs of iron-deficiency anaemia. Years before, a contrast $x$ ray examination of the colon with per rectal application of barium sulphate has revealed elongated and twisted sigmoid colon. Laboratory tests after admission showed low values of $\mathrm{Hb}(97 \mathrm{~g} / \mathrm{l})$ and Hct $(0.289)$, high ESR $(70 / 95 \mathrm{~mm})$ and slightly elevated CEA $(7.9 \mathrm{U} / \mathrm{ml})$ and CA $19-9(47 \mathrm{U} / \mathrm{ml})$. Abdominal sonography revealed hepatic steatosis without metastases and no gallstones. There were no other pathological findings. Colonoscopy revealed two tumours in the large intestine, almost obturating the lumen in the transverse and the sigmoid colon. Histologically, the two samples were determined as adenocarcinomata. Tumor locations are further confirmed by contrast axial abdominal computed tomography - Revolution Evo GE with Omnipack $100 \mathrm{ml}$. Intravenous and Urografin oraly, which further indicates that the carcinomas are a second radiological stage (Figures 1 and 2).

Figure 1: Tumour of transversal colon confirmed by abdominal CT

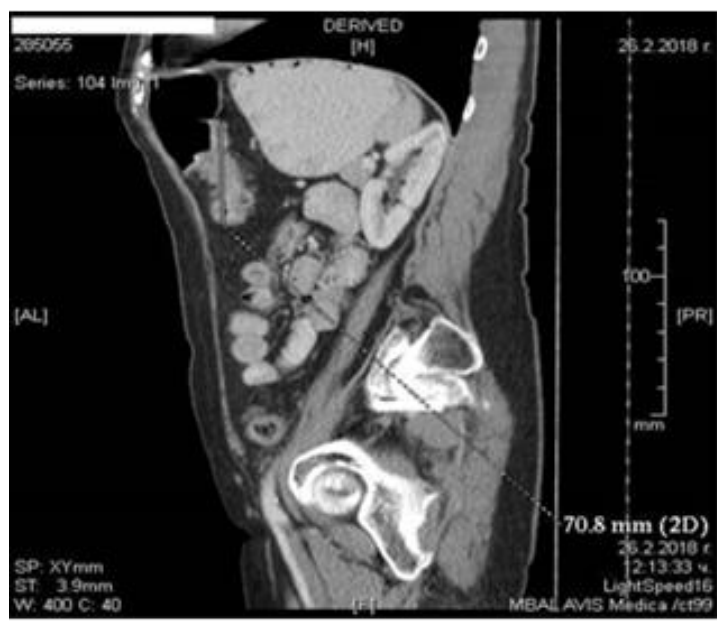

Figure 2: Tumour of sigmoidal colon confirmed by abdominal CT

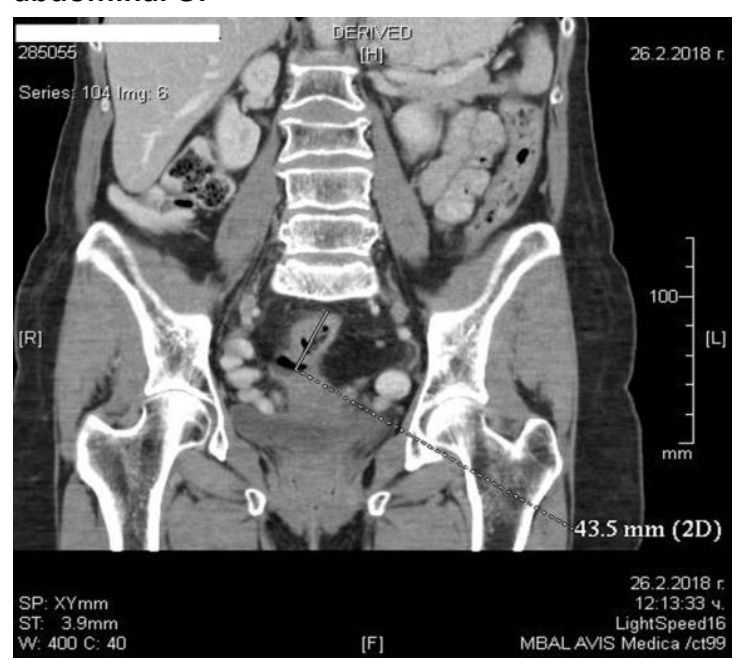

The case was reviewed by an oncological committee. The treatment strategy included surgical treatment, eventually followed by adjuvant chemotherapy. After discharge from the Clinic of Gastroenterology, the patient was referred to the clinic of surgery at Dr. Georgi Stranski University Hospital. Resection of the ascending, transverse, descending and sigmoid colon and the proximal third of the rectum was performed in compliance with all rules for surgical radicality (Figure 3).

\section{Figure 3: Colorectal resection with synchronous carcinoma}

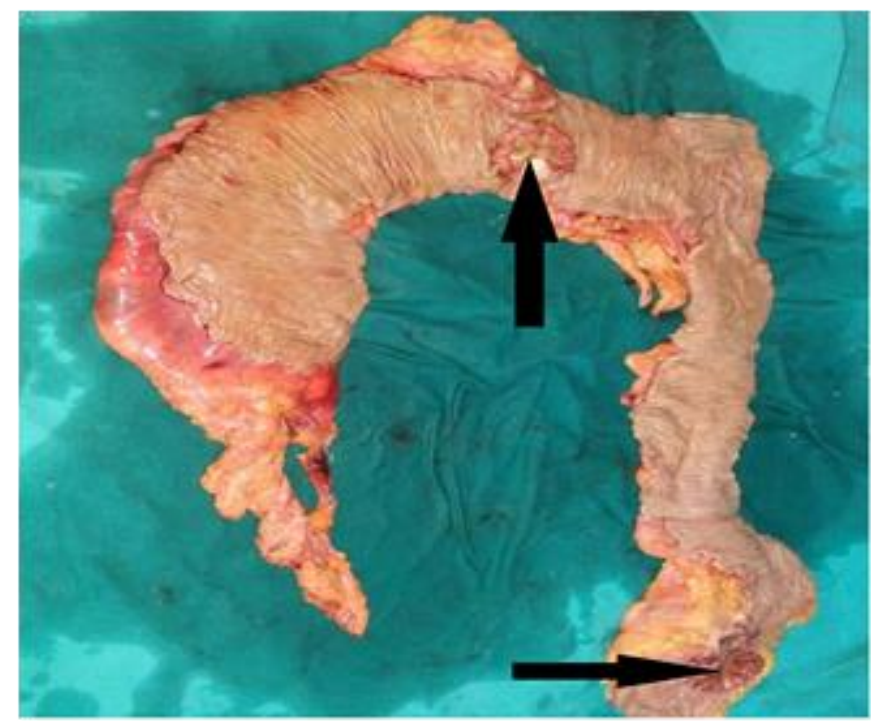

Bowel continuity was restored with a termino-terminal anastomosis between the caecum and the middle third of the rectum. The histopathological examinations with haematoxylin-eosin indicates that the transverse colon carcinoma was defined as a moderately differentiated adenocarcinoma, infiltrating the intestine wall, including the serosa, with no metastases in the removed 13 regional lymph nodes ( $\mathrm{PT} 3 \mathrm{NOMO}$ ) and that the sigmoid colon tumour was also moderately differentiated adenocarcinoma, noninfiltrating the serosa, and with diffuse metastases in 4 out of 7 regional lymph nodes ( $\mathrm{PT} 2 \mathrm{~N} 2 \mathrm{MO}$ ). After discharge, the patient was referred to the department of oncology for adjuvant chemotherapy with leucovorin calcium (folinic acid), 5FU and oxaliplatin (FOLFOX).

\section{Discussion}

Synchronous colorectal cancer is relatively rare, accounting for 3.5 per cent of all carcinomas of the colon and rectum. ${ }^{1}$ It is more often seen in males, as compared to females (ratio 1.8:1). ${ }^{2-6}$ The most frequently affected age group is of individuals aged $60-65 .^{7-11}$ In the case, we report the woman was 62-years-old. 
The most common predisposing factors for the development of synchronous colorectal carcinoma include inflammatory diseases of the intestines, hereditary nonpolypous colorectal carcinoma, family history of adenomatous polyposis and chronic ulcero-hemorrhagic colitis. ${ }^{13-16}$ In this case, the most likely predisposing factor was an inflammatory disease of the colon: the patient reports she had had abdominal discomfort and obstipation for the last few years.

Colorectal carcinomas usually affect the sigmoid colon and the rectum, and there is a specific difference regarding location between solitary and synchronous tumours. ${ }^{15}$ Compared to single carcinomas, synchronous more often affect the right half of the colon, which correlates with the right-sided dominance of some genetic colon diseases. ${ }^{17,18}$ In our case, the tumours were found in the transverse and sigmoid colon.

When tested pathologically, synchronous colorectal carcinomas are more often found to be mucinous adenocarcinoma, as compared to solitary ones. ${ }^{19}$ However, in the case in which we report, moderately differentiated adenocarcinomas have been found at both sites and, interestingly, the proximal tumour had penetrated deeper into the intestinal wall and affecting the serous, while the distal is more superficial and had infiltrated the muscle layer without affecting the serous. Moreover, the distal one had lymph nodes metastases, while the proximal did not.

When tested with molecular diagnostics, synchronous colorectal carcinomas show a high percentage of microsatellite instability of the genome. ${ }^{11,20}$

In the treatment of synchronous colorectal cancer, it is recommended to remove larger parts of the affected colon, considering the predisposing pathological conditions, such as chronic ulcero-hemorrhagic colitis, family history of adenomatous polyposis, etc., which affect a larger part of the colon. ${ }^{1}$ In our case, we fully complied with that rule, and resected almost the whole colon, excluding the caecum and the two distal thirds of the rectum.

In the complex treatment of synchronous colorectal cancer is very important the adjuvant chemotherapy, which in our case is in line with the guideline of NCCN.

The prognosis for synchronous colorectal carcinoma is significantly worse compared to that of the solitary localisation carcinoma. ${ }^{21}$

\section{Conclusion}

Synchronous colorectal carcinoma is sporadic. It usually occurs on top of other inflammatory and genetic diseases of the colon, and the sigmoid colon and the rectum are most often affected.

When treating synchronous colorectal carcinoma, mostly broadened resection techniques are used.

The prognosis for synchronous colorectal carcinoma is worse compared to that of solitary carcinoma.

\section{References}

1. Lam A, Chan S, Leung M. Synchronous colorectal cancer: clinical, pathological and molecular implications. World J Gastroenterol. 2014;20(22):6815-20.

2. Welch J. Multiple colorectal tumors. An appraisal of natural history and therapeutic options. Am J Surg. 1981;142:274-280.

3. Passman M, Pommier R, Vetto J. Synchronous colon primaries have the same prognosis as solitary colon cancers. Dis Colon Rectum. 1996;39:329-334.

4. Eguchi K, Yao T, Konomoto $T$, et al. Discordance of p53 mutations of synchronous colorectal carcinomas. Mod Pathol. 2000;13:131-139.

5. Chen H, Sheen-Chen S. Synchronous and "early" metachronous colorectal adenocarcinoma: analysis of prognosis and current trends. Dis Colon Rectum. 2000;43:1093-1099.

6. Ueda E, Watanabe T, Umetani N, et al. Microsatellite instability of cancers and concomitant adenomas in synchronous multiple colorectal cancer patients. J Exp Clin Cancer Res. 2002;21:149-154.

7. Langevin J, Nivatvongs $S$. The true incidence of synchronous cancer of the large bowel. A prospective study. Am J Surg. 1984;147:330-333.

8. Finan P, Ritchie J, Hawley P. Synchronous and 'early' metachronous carcinomas of the colon and rectum. Br J Surg. 1987;74:945-947.

9. Takeuchi H, Toda T, Nagasaki S, et al. Synchronous multiple colorectal adenocarcinomas. J Surg Oncol. 1997;64:304-307.

10. Bekdash B, Harris S, Broughton C, et al. Outcome after multiple colorectal tumours. Br J Surg. 1997;84:14421444.

11. Hu H, Chang D, Nikiforova $M$, et al. Clinico-pathologic features of synchronous colorectal carcinoma: A distinct subset arising from multiple sessile serrated adenomas and associated with high levels of microsatellite instability and favorable prognosis. Am J Surg Pathol. 2013;37:1660-1670. 
12. Brambilla E, Sgarioni A, Finger G, et al. Incidence and epidemiological features of synchronous and metachronous colorectal cancer. J Coloproctol. 2013;33(2):58-61.

13. Greenstein A, Slater $G$, Heimann $T$, et al. A comparison of multiple synchronous colorectal cancer in ulcerative colitis, familial polyposis coli, and de novo cancer. Ann Surg. 1986;203:123-128.

14. Remzi F. Colorectal cancer complicating inflammatory bowel disease: similarities and differences between Crohn's and ulcerative colitis based on three decades of experience. Ann Surg. 2010;252:330-335.

15. Lam A, Carmichael R, Gertraud Buettner P, et al. Clinicopathological significance of synchronous carcinoma in colorectal cancer. Am J Surg. 2011;202:3944.

16. Liu X, Goldblum J, Zhao Z, et al. Distinct clinicohistologic features of inflammatory bowel disease-associated colorectal adenocarcinoma: in comparison with sporadic microsatellite-stable and Lynch syndrome-related colorectal adenocarcinoma. Am J Surg Pathol. 2012;36:1228-1233.

17. Kaibara N, Koga S, Jinnai D. Synchronous and metachronous malignancies of the colon and rectum in Japan with special reference to a coexisting early cancer. Cancer. 1984;54:1870-1874.

18. Eu K, Seow-Choen F, Goh H. Synchronous colorectal cancer in an Oriental population. Int J Colorectal Dis. 1993;8:193-196.

19. Adloff M, Arnaud J, Bergamaschi R, et al. Synchronous carcinoma of the colon and rectum: prognostic and therapeutic implications. Am J Surg. 1989;157:299-302.

20. Aslanian H, Burgart L, Harrington J, et al. Altered DNA mismatch repair expression in synchronous and metachronous colorectal cancers. Clin Gastroenterol Hepatol. 2008;6:1385-1388.

21. Nosho K, Kure S, Irahara N, et al. A prospective cohort study shows unique epigenetic, genetic, and prognostic features of synchronous colorectal cancers. Gastroenterology. 2009;137:1609-20.

\section{PEER REVIEW}

Not commissioned. Externally peer reviewed.

\section{CONFLICTS OF INTEREST}

The authors declare that they have no competing interests.

\section{PATIENT CONSENT}

The authors, Strashilov S, Yordanov A declare that:

1. They have obtained written, informed consent for the publication of the details relating to the patient(s) in this report.

2. All possible steps have been taken to safeguard the identity of the patient(s).

3. This submission is compliant with the requirements of local research ethics committees.

\section{FUNDING}

This publication is supported by Project N BG05M2OP0012.009-0031-C01 